\title{
Chapter 9 \\ Helping Teacher Educators in Institutions of Higher Learning to Prepare Prospective and Practicing Teachers to Teach Mathematics to Young Children
}

\author{
Herbert P. Ginsburg
}

\begin{abstract}
Research shows that young children possess surprising mathematical abilities and can benefit from Early Mathematics Education, which can lay a sound foundation for mathematics learning. Yet institutions of higher education generally provide their students with inadequate preparation in teaching mathematics to young children. To ameliorate this unfortunate situation, I have been working with colleagues on development of a comprehensive set of materials that teacher educators - usually professors and instructors in institutions of higher learning - can use in their teaching, either live or online. This paper describes a framework for training teacher educators and their students and presents an account of materials that can be used to promote understanding of the relevant mathematics, mathematical thinking of young children, and the kind of formative assessment that can be useful for teachers.
\end{abstract}

Keywords Professional development • Early mathematics education Mathematical thinking $\cdot$ Formative assessment $\cdot$ Higher education

\subsection{Introduction}

In this paper, I describe the need for rich programs of teacher preparation in Early Mathematics Education (EME). Quality EME can lay a sound foundation for mathematics learning and also satisfy children's curiosity about numbers, shapes, and other mathematical topics. Yet, I argue, institutions of higher education generally do not prepare their students adequately for EME. They often fail to provide prospective and practicing teachers with an understanding of young children's mathematical thinking and the pressing need to foster it. To ameliorate this unfortunate situation, I have been working with colleagues on development of a

\footnotetext{
H. P. Ginsburg $(\bowtie)$

Teachers College Columbia University, New York, NY, USA

e-mail: ginsburg@tc.edu

(C) The Author(s) 2018

G. Kaiser et al. (eds.), Invited Lectures from the 13th International Congress

on Mathematical Education, ICME-13 Monographs,

https://doi.org/10.1007/978-3-319-72170-5_9
} 
comprehensive set of materials that teacher educators-usually professors and instructors in institutions of higher learning — can use in their teaching, either live or online. Before introducing what we have developed, and the rationale for it, I describe the urgent need for an improved EME as well as some challenges we must overcome to implement it. I argue that it is clear that young children possess surprising mathematical abilities and can benefit from EME, if only the teacher educators and their students are properly prepared to understand and implement it. Then I describe a framework for training teacher educators and their students and present an account of the new materials we are developing with the collaboration of colleagues. ${ }^{1}$

\subsection{The Need for EME}

Many countries around the world stress the need for strong and extensive programs of EME. In the U.S., "Early childhood education has risen to the top of the national policy agenda with recognition that ensuring educational success and attainment must begin in the earliest years of schooling" (Cross et al. 2009). Latin American countries express similar concerns: "We have to do something [about EME], especially in the countries that were the land of brilliant civilizations like the Mayans and the Incas, who made important scientific and mathematical contributions" (Bosch et al. 2010, p. 5). Improving early mathematical competence has become a major priority around the world (Platas et al. 2016).

Why this focus on EME? One reason is that it has become increasingly clear that early proficiency in mathematics is a good predictor of academic success in later years (Duncan et al. 2007) and even college attendance (Duncan and Magnuson 2011). Further, "A causal relationship has been identified between early mathematical proficiency and later individual economic well-being and broader economic growth in countries including Kenya, Tanzania, Ghana, and Pakistan..." (Platas et al. 2016, p. 164).

We would add another important reason for EME, namely that failing to provide it is a disservice to young children. They are curious about mathematical ideas and want to learn. Contemporary developmental and educational research (Sarama and Clements 2009) shows that young children develop a relatively powerful informal mathematics as well as the capacity to acquire rather sophisticated foundational math skills. From the earliest days of infancy, they develop an everyday mathematics of some power and complexity. Infants can identify a collection containing more objects than another contains. Parents can easily confirm that babies prefer

\footnotetext{
${ }^{1}$ This work was done in collaboration with Megan Franke, Linda Platas, and Deborah Stipek, all of whom are members of the Development and Research in Early Mathematics Education (DREME) project, generously funded by the Heising-Simons Foundation. We are grateful for the Foundation's support. I also want to acknowledge the contributions of my students, Ma. Victoria Almeda, Bona Lee, Myra Luna-Lucero, Colleen Oppenzato, Colleen Uscianowski, and Eileen Wu.
} 
more food to less. Babies approve of the parent adding food, and make clear their displeasure when some is taken away.

From about 2 years to 6 , children engage in even more complex mathematical activities. Knowing a fair number of counting words, they develop ideas about "how many?" They learn, sometimes without adult assistance, to assign the counting words, one at a time, in order, to one and only one object. As they grow older, they gradually learn that the last number in the count sequence indicates the set's cardinal value and thus answers the "how many" question (Baroody and Dowker 2003).

Young children also enjoy their everyday mathematics. It is part of their intellectual life. It satisfies their curiosity. They do not need EME to make them ready for learning mathematics. Their everyday mathematics is real mathematics, involving thinking and exploration as well as the necessary memorization (for example of the numbers from one to ten).

Given young children's ability and potential to learn, promoting their mathematical learning should be a critical component of high quality early childhood education. Although preparation for the future is vital, we should also help children thrive in the present by providing them with the appropriate mathematical food for thought. If the focus is mainly on the future, one result may be high stakes testing, which may have the effect of deadening teaching and learning during the early years. But a focus on the present will not only respond to children's current interests but also help prepare them for future school success.

Given its importance (in the present as well as in the future), early mathematics proficiency is alarmingly inadequate around the world. "[A]t least 250 million primary-school age children around the world are not able to read, write or count well enough to meet minimum learning standards (Center for Universal Education at Brookings and UNESCO Institute for Statistics 2013, p. 1), including those who have spent at least four years in school. Further, "Of the more than 800 millions 0 to 6 year old children in the world, less than a third benefit from early childhood education programmes" (Lillemyr et al. 2001, p. 1).

Socio-Economic Status (SES) and ethnic differences in early mathematics proficiency exist in many countries. In the U.S., low-income and African-American children perform more poorly than middle-income and mainstream children (Denton and West 2002; Love and Xue 2010).

Given the low levels of mathematics performance, especially in lower-SES and minority children, and given the importance of early mathematics learning, many education authorities around the world (Bosch et al. 2010) have called for the widespread, even universal, implementation of high quality mathematics education for young children by at least the age of 4 years, especially for low-income children at risk of school failure (Cross et al. 2009) and of attending failing schools (Ginsburg et al. 2008). Meeting the educational needs of young children requires many different kinds of contributions, including:

- Political: The public needs to decide that early education is a social priority and should be universally available. 
- Economic: The public needs to devote adequate public funding for classrooms, teachers and assistants, meals, and related needs.

- Resource Development: Educators need to create rich materials for children's mathematics learning.

- Teacher Education: Institutions of higher learning need to prepare teachers for EME and school systems need to support teachers who are engaged in implementing it.

- Research: Educators and psychologists need to understand the basic processes of EME and evaluate their efficacy.

Fortunately, many efforts along these lines are already underway. As we saw, many education authorities have called for extensive EME and are devoting funds to pay for it. Educators and researchers and others have developed and evaluated rich mathematics curricula (Casey et al. 2004; Ginsburg et al. 2003; Griffin 2004; Sarama and Clements 2004; Sophian 2004; Starkey et al. 2004).

One area that has received relatively little attention is pre-service education. Prospective teachers are seldom given adequate preparation in EME at the level of higher education (Ginsburg et al. 2014). The Development and Research in Early Mathematics Education (DREME) project aims to provide teacher educatorsprofessors, instructors, and others-with effective EME pedagogy and materials that can be used in a flexible manner, in different courses, to prepare their students, prospective teachers, for EME.

\subsection{A Guide for Teacher Educators}

William James had it right over a hundred years ago (1899) when he wrote: "Psychology is a science, and teaching is an art; and sciences never generate arts directly out of themselves. An intermediary inventive mind must make the application, by using its originality" (James 1958, pp. 23-24). That is, although science may provide insights into children's mathematical thinking and learning, teachers need to use their "intermediary inventive mind[s]" to construct understandings of individual children and ways of teaching them. Our overall goal is to help teacher educators to prepare and support thoughtful, critical minded students.

\subsubsection{What Do We Teacher Educators Want Our Students to Know?}

The teaching of virtually any subject is complex, difficult and intellectually challenging. To teach well, our students need to learn a great deal about several interesting topics. 


\subsubsection{The Mathematics}

It is self-evident that teachers need to understand what they attempt to teach. The problem, however, is that many students, and adults generally, do not realize that the mathematics young children need to learn is not simple. Indeed this basic mathematics - including whole number, shape and space-is far more complex than many adults recognize, precisely because it deals with basic ideas. Addition of the whole numbers, for example, is much more than remembering number facts, like the sum of 2 and 3. Addition also involves a set of fundamental mathematical ideas. For example, the child should know that the sum of any two numbers (other than zero) must be greater than each; that the order of adding makes no difference; that the sum indicates the total number of objects; that addition can be used to model certain real situations; and that methods for calculating a sum can and should make sense. These ideas are not hard for adults to learn, but many prospective teachers do not think about early addition in these terms and hence cannot teach the subject effectively.

\subsubsection{The Development of Mathematical Thinking}

How can anyone teach effectively without understanding the students to be taught? Would any teacher want not to understand her students? Teachers of young children in particular need to understand their thinking because it often differs from our own. The idea of distinctive child thought was one of the central points of Piaget's theory (Piaget and Inhelder 1969). We are surprised, and sometimes amazed and amused, to encounter a child who thinks that moving around a group of objects, without adding or taking away any of them, results in a change in the group's number, because we do not see the world in the same manner. Effective EME requires teachers to take a cognitive leap from their own ways of thinking, in order to understand the child's. In a sense, teachers need to overcome their own egocentrism to see the child's.

The psychology of children's mathematical thinking is very rich. Inspired by Piaget's theory (Piaget 1952), contemporary research has illuminated key aspects of everyday and formal mathematics learning (Sarama and Clements 2009). We now know in great detail how children think about the topics central to EME: basic number, shape, space, pattern, and measurement. The research has also plotted the developmental trajectories of thinking related to these topics. It is important to note that current research goes far beyond general Piagetian ideas about broad stages of development, like pre-operational and concrete-operational thought. Current research offers insight into the development of specific aspects of mathematical thinking, both everyday and schooled. This was not something that Piaget tried to do. Surely our students need to understand the details of student thinking and how it develops. 


\subsubsection{Formative Assessment and Understanding the Individual}

Formative assessment is the process of collecting information that enables the teacher to understand individual children and to use what has been learned to improve instruction (Heritage 2010). Formative assessment is different in several ways from summative assessment, like achievement tests, year-end testing, or other forms of high-stakes assessment that use standard tests to focus mainly on children's achievement and mastery. By contrast, formative assessment employs flexible, and deliberately non-standardized methods, primarily clinical interviews and observations, to focus not only on performance, which of course is important, but also on what underlies it, namely children's ideas and strategies, knowledge of which can be used to shape teaching. Formative assessment is relevant for teachers, whereas summative assessment provides them with little actionable information.

It is important to note that the target of formative assessment is the individual child, not the average or prototypical child pictured by a developmental trajectory. Yes, 4-year-olds can be characterized in general as doing so and so. This is valuable information, but there is variation within the group, so that the prototype may not fully apply to the individual. Given the fact of widespread individual differences, the teacher needs to understand and assess the individual child.

\subsubsection{Pedagogical Goals and Methods}

Students need to learn that the overarching pedagogical goal is to produce meaningful learning in which children synthesize what they already know, their everyday mathematics, with the more powerful formal mathematics developed over the years in different cultures, from the Indian to the Arabic to the Western.

Vygotsky (1986) put the matter thus: "In working its slow way upward, an everyday concept [everyday mathematics] clears a path for the scientific concept [formal mathematics] and its downward development. It [the scientific concept] creates a series of structures necessary for the evolution of a concept's more primitive, elementary aspects, which give it body and vitality. Scientific concepts, in turn, supply structures for the upward development of the child's spontaneous concepts toward consciousness and deliberate use... The strength of scientific concepts lies in their conscious and deliberate character. Spontaneous concepts, on the contrary, are strong in what concerns the situational, empirical, and practical" (p. 194).

In other words, the goal of our pedagogy should be help the child develop a meaningful synthesis of the personal, which offers "body and vitality," and the formal, which is conscious and deliberate. The synthesis allows the child to "own" the resulting mathematical knowledge.

Accomplishing this goal requires several pedagogical approaches, and our students need to understand them all. Students need to appreciate the appropriate roles of free play, exploration, projects, guided instruction, group discussion, verbalization of ideas, memorization, and curriculum. These are all useful to the extent that they promote effective EME, each in their own ways. Thus free play can excite 
interest in mathematical ideas, but intentional teaching may be necessary for the child to understand them in depth.

\subsubsection{Overcoming Negative Feelings}

Unfortunately, many students, at least in the U.S., have negative feelings about mathematics. They experience anxiety about learning, doing, and teaching mathematics. Indeed, some students say that they chose the profession of early childhood education so that they would not have to teach mathematics. They may transmit negative feelings to the children they teach (Beilock et al. 2010). Clearly one of the teacher educator's goals must be to help students overcome their math anxiety. It's also true that some teacher educators may feel this kind of anxiety. To you, I can only say that the course materials may help you to overcome yours as well.

\subsection{The DREME Modules}

Our DREME project ${ }^{2}$ has, to date, produced five modules, namely basic number (including counting words, enumeration, and cardinality); geometry (including shape and space); operations (including addition/subtraction and division into fair shares); pattern (including growing patterns); and measurement (informal and exact). In each module, the materials include:

- Readings on aspects of EME, some specially created for these modules,

- Explanations of the basic mathematics,

- Accounts of children's mathematical thinking and learning, with accompanying videos,

- Analyses of teaching, with accompanying videos,

- Guides to assessment, with accompanying videos,

- Guides to picture book reading from a mathematical point of view, with videos,

- Activities for higher education classroom use, with accompanying videos, and

- Vignettes of adult experiences related to EME.

Our general pedagogical approach is this: As much as possible, TEs should help adult students learn in the same way that we want teachers to help children learn. TEs need to engage students in active learning that bridges the gap between theory and practice, and that gives personal meaning to the concepts learned in the course.

We designed the modules for flexible use. TEs can use one component of a module in a course on science education; several components in a math methods course; or another component in a general introduction to Early Childhood

\footnotetext{
${ }^{2}$ http://prek-math-te.stanford.edu/.
} 
Education. I now illustrate the modules, along with some methods of my own, through a personal use case: an account of my own teaching.

\subsection{My Course}

My course, The Development of Mathematical Thinking meets once a week, for $1 \mathrm{~h}$ and $40 \mathrm{~min}$, over a period of 14 or 15 weeks, and also includes a web based component. The course (despite its name) uses many of the DREME materials to focus not only on children's mathematical thinking but also on early childhood pedagogy. Of course, few TEs will want to teach the course exactly the way I do, but they may choose DREME activities that help them meet their own goals and are consonant with their backgrounds. Indeed, this flexibility is exactly the goal of our DREME project.

Almost all of my students are prospective teachers at the Masters level in a Department of Curriculum and Teaching. Clearly these students are different from undergraduate education majors, but they do share an interest in teaching young children. The course (or the equivalent) is highly recommended for Early Childhood Education students.

\subsubsection{Who Are You?}

At the outset, like many TEs, I am interested in learning about the students taking the course. I have used several methods to learn about their interests, their background, and their feelings towards mathematics and EME. In my experience it is particularly useful to explore their anxieties about the course, particularly because some students may have been reluctant to take it in the first place.

The DREME materials include an activity dealing with student feelings. It begins with students reading a vignette called But, I'm not good at math! (Platas electronic document-a), which describes student fears and anxieties about teaching mathematics to a young child. The reading is followed by an activity, "Engaging Mathematics" Activity, (Platas electronic document-c), that helps students address and understand their feelings, beliefs, and attitudes, and thus begin the process of developing a positive approach to teaching mathematics.

I conduct a similar classroom discussion activity. During the first class I initiate a discussion of their ideas about and feelings toward EME. My intent is to help students understand that others may also have had traumatic (not too strong a word) experiences in their mathematics classes and still fear learning and teaching it. I also want them to know that I am concerned about their feelings and will try to help. I say that they should be patient because over the course of the semester, as they discuss the mathematics and children's responses to learning it, they will begin to shed their fears and in fact will find EME intriguing. I ask the students to send 
me, before the next class, a reflection on this activity. To insure confidentiality, I do not reveal the authors of the following typical quotes:

I was concerned that I was going to be the only person that wasn't good at math coming into the course.

Overall, this week's [class] made me realize that I am not alone in my feelings of discomfort surrounding teaching math in the classroom.

I, myself, have had a negative outlook towards math and have always tried to avoid dealing with anything to do with math.

\subsubsection{What Concerns You?}

As a TE, I want to monitor my students' learning throughout the semester. Of course, I talk with them during class, ask questions, and the like, but sometimes students do not feel comfortable revealing their ideas or concerns to others in a group setting, particularly if the class is large.

For this reason, I require students to submit on our course website, after each weekly session, a short, ungraded reflection on what they learned in the previous class. Usually students are urged to discuss anything they found important or arguable. Occasionally I may ask them to discuss a specific issue. Before the next class, I read all of the reflections and send brief comments to each student. Then, at the outset of the next class, I show (via a projected PowerPoint) and discuss with the students parts of 4 or 5 reflections carefully selected to raise important issues. Here are some examples:

1. "For the past two classes now, what has really stood out to me is how much one can analyze from just 1-1.30 min of a video. Even the smallest details, from a glance to a slight hesitation, are indicative of something much larger. I wonder, though, how this would be possible in a classroom with 10 or 15 children, each one making several such gestures that indicate a thought, feeling or strategy. If only life had a pause and rewind button, then I could effectively analyze the mathematical thinking occurring in the classroom without missing a beat."

2. "I think symbols can give children different feelings depending on the scenarios in which they are presented. For example, exposing a child to symbols in a classroom setting and telling them that they must memorize these symbols can come off as very stressful and hard. But showing children symbols in everyday experiences can be less stress inducing and even fun, while also giving the children a visual representation of what certain symbols can mean; thus making the symbols less foreign for them to understand. I think that even taking children on walks as a field trip, allowing them to experience these symbols (and ask questions about such if they are so inclined) could be a great learning experience for young children living in any area." 
3. "I think the thing that struck me the most was the highly detailed critique that we did of even just the first few pages of the storybook [name deleted]. It's just so surprising how many flaws that we were able to come up with as a class in about $20 \mathrm{~min}$ that this book had, and that such flaws were not taken into account prior to publishing this children's book."

As is evident, the student reflections provide the TE with opportunities to discuss and expand upon interesting issues. Thus the TE can use the first reflection to discuss a very real dilemma, namely how difficult it is for a teacher to attend to the activities of some 10 or 15 children, and to suggest possible solutions (for example, a plan to spend 5 min carefully observing each of 4 students a day). The TE can use the second reflection to dig more deeply into the nature of mathematical symbols and methods to help children learn them in meaningful and enjoyable ways. This reflection also allows students to draw conclusions about the differing value of activities depending on their context. The TE can use the third reflection to raise the issue of strategies for storybook reading, including how to deal with pages that are unclear or incorrect.

I have discovered that the post-class reflection offers the students a distinctive form of digital intimacy. After seeing that I take the reflections seriously and that the class discussions are interesting and useful, students begin to write lengthier reflections and to reveal in them insecurities and areas of ignorance, as well as questions about the readings, and comments on my lectures or other class events. Also, students get excited (and I think feel pride) when their reflections have been chosen for class discussion. The reflections provide me with insights into student needs, confusing remarks I may have made, and issues I had not considered. Sometimes a reflection teaches me something new about the subject matter-the children and also the mathematics.

\subsubsection{Learning About the Math}

Recognizing that many students are fearful of mathematics, the DREME modules contain several approaches to teaching number and geometry.

One approach is traditional. We have created some readings on the relevant mathematics, including a short piece on The Mathematics of Counting, (Platas electronic document-b) and What Young Children Know and Need to Learn about Number (Ginsburg electronic document-f), that discuss the mathematics to be learned in relation to children's existing knowledge.

DREME also offers classroom activities in which TEs can have adult students solve some mathematics problems, reflect on what they learned, and relate their learning to children's (Franke electronic document). This method helps teachers to see the world of mathematics from the learner's point of view. 
Finally, I urge TEs to make the acquaintance of Professor Ginsboo (Ginsburg electronic document-e), who presents students with a hopefully amusing and engaging introduction to basic mathematical ideas from the perspective of a child trying to learn them. We find that some students and TEs find this approach useful, and others don't know what to make of it. We intend to investigate the appeal and effectiveness of the good Professor.

\subsubsection{Learning About Children's Thinking}

Students need to learn about the general trajectory of children's thinking during the early childhood years and beyond. The 3-year-old child's concept of "how many?" is very different from that of the 5-year-old's. Fortunately, researchers have contributed enormous insights into the nature and development of mathematical thinking during this age range.

One way for students to learn about the trajectory is to read relevant papers. Although this is valuable, our DREME project offers what we think are more engaging written accounts with built in videos. We call them "Thinking Stories" because they use a narrative form to present key aspects of mathematical thinking. One such thinking story describes a young boy's understanding of "how many?" as revealed by clinical interviews conducted when he was 3-, 4-, and 5-years of age (Ginsburg electronic document-a). This story, a kind of longitudinal case study, is particularly dramatic because it involves videos of the same child throughout.

Videos of young children are memorable. Former students have told me years later that they still remember several course videos. The DREME project offers on its website many videos that can be used to illustrate children's thinking and learning. You and your students can make such videos as well.

\subsubsection{Assessment}

TEs need to help students to understand individual children's behavior and thinking. Students need to learn to observe carefully, to think critically about what they see, develop reasoned interpretations, and use those interpretations to guide teaching. I use several methods for accomplishing these goals.

\subsubsection{Analyzing Videos}

One approach, which I use in almost all class sessions, is to engage the class in the analysis of videos, usually involving clinical interviews and observations of behavior. I use the "pedagogy of the video clip," which works as follows. 
Imagine that you are in front of your higher education classroom. The topic is Counting. You say that the class will discuss a video illustrating key aspects of both the child's counting skill and knowledge, and the interviewer's method. The students' task is to examine the video carefully, develop an interpretation of what the child does and does not understand about counting, and consider how this interpretation can guide teaching. The students also examine the interviewer's clinical interview technique.

The video you use meets several essential requirements. First and foremost, the content illustrates children's thinking and learning of the mathematical topic of interest. Further, the video is intriguing, attractive, dramatic, and sometimes even funny. It is not too long (usually under two minutes). It grabs students' attention and animates what they read for their assignments. The video is a kind of intellectual manipulative with which students can explore children's thinking and construct a meaningful understanding of it.

Yet by itself the video, no matter how wonderful, is not sufficient. You, as the instructor, should not simply show the entire video, tell the students what you think it means, and then go on to the next topic. Instead you need to use and exploit the video as effectively as possible to promote your students' careful observation, analytic thinking, judicious interpretation, and consideration of productive instructional activities.

The essence of the pedagogy of the video clip is to:

- Show your students carefully selected segments of the video;

- Help students observe carefully;

- Repeat a segment or part of it to clarify observations and hypotheses;

- Ask students for interpretations supported by evidence;

- Challenge their interpretations;

- Encourage students to justify their interpretations;

- Ask students to evaluate classmates' interpretations;

- Do not allow students to get away with vague generalities, like "She is in Piaget's preoperational stage" or "His behavior is developmentally appropriate";

- Use flexible questioning to reveal the thinking behind your students' interpretations;

- Encourage the students to discuss and challenge interpretations, offer possible alternative hypotheses, and propose instructional approaches based on what has been learned about the child's understanding;

- And finally, help your students to relate the lessons learned from the video to academic papers and ideas concerning children's mathematical thinking and learning.

Examining videos in this fashion may be more effective than observing children directly or reading about children's thinking. A video is worth many more than a thousand words. The video allows you to view and review, to go forward and backwards in time, and to engage in deliberate and unhurried contemplation of the evidence. By comparison, direct observation is ephemeral and does not afford the 
kind of careful study provided by videos of thinking and learning. Hence, the DREME project offers a video-based introduction to the pedagogy of the video-clip (Ginsburg electronic document-d).

\subsubsection{Clinical Interview}

One of the most effective methods of formative assessment is the clinical interview, in which the adult uses flexible questioning to uncover what the child knows. Piaget's experience with the development of Binet's IQ test taught him that standardized tests are not particularly effective in uncovering cognitive processes; he felt that answers to IQ test items were ambiguous and required further examination by means of the clinical interview (Piaget 1976), which typically begins with a task chosen by the adult. Then the interviewer observes the student's response, behavior, affect and anything else that might be relevant, and develops an interpretation of the processes underlying the student's behavior. To check the interpretation, the interviewer develops new tasks as appropriate, follows up with questions designed to elicit thinking, and in general follows the student's thought process to where it leads. The interviewer sometimes challenges the student's response ("But Johnny said that 2 and 2 is really 5") to assess its stability and the student's confidence in it. The interviewer may sometimes employ gentle hints to help the student overcome a difficulty ("Can you use your fingers to help you figure it out?"). The interviewer continues these non- standardized investigative maneuvers, which must be constructed on the spot, in real time, until enough evidence has been obtained to support a reasonable interpretation of the student's behavior. If done well and guided by appropriate theory, clinical interviews can provide deep insights into thinking and can reveal strengths and weaknesses that otherwise may go undetected (Ginsburg 1997).

The students become familiar with the clinical interview almost each week as we discuss videos, most of which involve an adult interviewing a child. Although most of the analysis centers on children's thinking, we often examine, in some detail, the interviewer's technique.

Students are also required to complete a mid-term assignment in which they conduct and video record a clinical interview with a child. At this point, the students are impressed by the power of the interview to reveal hidden features of a child's thinking. But they are also apprehensive at the prospect of conducting an interview themselves, especially when they are required to video-record it and use clips from the video to justify their analyses. I tell the students to be brave and to go out and do the interview, and that everyone makes mistakes in interviewing, which is a complex skill.

In addition to cheerleading, I provide the students with various DREME materials: a general guide to interviewing, which we call math-thinking conversations, along with a sample interview protocols describing a series of questions and prompts that the student might use or modify (Ginsburg electronic document-b); 
and a voice over analysis of a video recording showing a teacher's excellent interview with her preschool student (Ginsburg electronic document-c).

The details of the interview assignment are worth describing in detail. The student is required to write on the class website a paper that shows what the interview revealed about the child's thinking. The paper (available only to the instructor) begins in a standard way with an overall introduction to the problem, a very brief review of the literature, a statement of the goal, a description of the initial protocol (which the student is encouraged to modify as necessary in response to the child's responses), and a description of the child and the testing conditions (for example, the interview was conducted in a quiet part of the classroom). All of this is conventional.

But the next part, the results, takes advantage of a video technology that allows students to make short clips from the interview and insert them where appropriate to buttress their interpretations. The students provide an interpretation and then justify it with a carefully selected video clip of the child's response. The students essentially have to provide an argument and justify it with evidence from the video. I see this as promoting students' critical thinking skills - their use of evidence to justify an argument, or to show that the interpretation is not clear and requires further evidence to resolve. The assignment is also designed to help students avoid vague interpretations, empty concepts, and fuzzy thinking. When I grade the papers I can not only read what the students wrote but also view their videos, which may or may not support their arguments. Below is an example of a student response (Fig. 9.1).

Clinical interviewing can be a rewarding activity for the child as well as the interviewer. My student Catherine Rau wrote this about a 4-year-old whom she had interviewed a few weeks earlier.

happens. Blalso has a pointy edge Sawyer only identifies the triangle by regarding one of its corners to be pointy. He shows no mention of it's straight lined sides, or its two other corners. Again, attempting to get more out of Sawyer than his "pointy edge" definition I show him a different shape. Btriangle and a heart I chose to show Sawyer an upside down heart, emphasizing it's pointy edge, interested to see how he would classify it or if he would potentially verbalize more attributes of a triangle. Bwe have 4 triangles But rather than defending the shape as a heart or a triangle, Sawyer explained that it was both. It was a heart right side up; and it was a triangle because it had a pointy edge, but a special triangle because of it's bottom. Here we can see that Sawyer's triangle schema has a hole in it. He is unaware of a triangle's attribute of possessing three straight lined sides. BThey're all triangles After presenting Sawyer with the next activity of identifying triangles on the triangle-esque filled worksheet, I found that hole to be bigger than expected. He identifies every shape on the worksheet to be a triangle, pointing out each shape's pointy edge. Again, the importance of children learning shape's attributes over their names is shown in this instance (Ginsburg, 1989). The last triangle exercise I chose to do with Sawyer was for him to draw a triangle. Bl can't write a triangle I wanted to make es ire that I was nivinn Sawver ennt inh avenu ues to

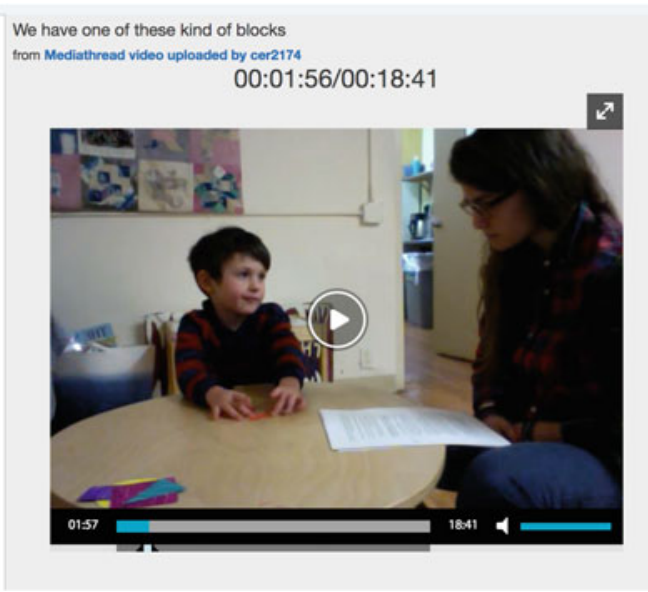

Fig. 9.1 Student assignment 
But it wasn't until Sawyer approached me at school randomly, the other week, to ask when we would be doing math again together, that I knew I absolutely had to interview him. He told me that he really liked learning math with me and that he wanted to do more fun math games and for even longer this time. ... I couldn't help but smile and agree to do more math with $\operatorname{him} . .$.

So the student can use the results of the interview to understand individual children and the children can enjoy the process of being interviewed. They seem to appreciate the attention of an adult who is interested in their thinking - how rare is that! - and the opportunity to solve interesting problems. For both adult and child, this is a win-win situation, clearly different from most high stakes assessments, which too often are lose-lose.

\subsubsection{Pedagogy}

The course naturally considers pedagogy. We have sessions and readings on the nature and value of pedagogy and curriculum for EME. My general approach is "constructivist," but I argue that it is important to consider the specifics of teaching, namely the particular maneuvers and methods that teachers use for different purposes (Ginsburg and Amit 2008). The argument is that teachers need to use a variety of methods to achieve the goal of children's meaningful construction of knowledge. Under some circumstances and for certain topics, free exploration is effective. At other times, direct instruction is desirable. For example, teaching the first 10 number words requires giving students basic practice that can facilitate memorization. At other times, the teacher may tell the child what to do- "I want you to make a color pattern with these blocks." There is a time for "telling" (Schwartz and Bransford 1998). The most important point for our students is to avoid being doctrinaire, and instead to attempt to match a teaching method with the needs of a child. If free exploration is what that child needs, fine. But if he needs drill to further the construction of knowledge, that is fine too.

Our DREME project makes available some teaching videos on its web site. In my class, we use analytic techniques, like the pedagogy of the video clip, to examine interesting cases of teaching.

Students are often skeptical about using curriculum for EME, even though several are available. I try to convince the class that using a planned curriculum is not necessarily "developmentally inappropriate." Because it is not the job of a higher education course to teach a particular curriculum, we examine examples of curriculum activities-from manipulatives to textbooks.

The course final project is designed to integrate what students have learned about children's thinking and about effective teaching and interviewing. Students engage in and video-record a three-part exercise in which they interview a child on a particular mathematical topic, teach what the child does not understand about the topic, and finally interview the child again to see what was learned. All of this 
provides the material for web-based papers in which students analyze the child's knowledge at each point, as well as their own teaching and interviewing.

\subsubsection{Picture Books}

Everyone loves children's picture books like Goodnight Moon (Brown and Hurd 2007). Parents snuggle up with their children at the end of the day to read books like these, sometimes over and over again. Teachers enjoy reading picture books to the whole class, at circle time, and also to the individual child or small groups of children. Children may want to read books over and over again (taxing parents' and teachers' literary patience). How many times has Moon gone to sleep?

Most picture books involve art and narrative. Some present simple exposition, not stories, as in the case of a book displaying different kinds of vehicles, from bicycles to fire trucks. But all these books for young children use pictures.

Reading books of this type can promote children's mathematics learning. Consider three types of picture books: those in which the mathematics is explicit, those in which significant mathematics is implicit, and everything else.

Explicit mathematics books are written for the express purpose of teaching children mathematics and may even contain a reference to mathematics in their titles, as in the case of counting books like, Anno's Counting Book (Anno 1977). Many books clearly written to teach mathematics do not have such titles, like Rooster's Off to See the World (Carle 1987), in which a different number of animals joins Rooster on each page, and children are invited to add up the total number of animals.

Other picture books were not written to teach children mathematics. However, they still address significant mathematical concepts in the narrative and illustrations. A well-known example is the classic story, Goldilocks and the Three Bears, which involves size comparisons (for example, the big bear, the medium-sized bear and the little bear) and correspondences (little bear with little bed and so on) that are crucial to the plot.

Finally, we have the rather large category of "everything else." The basic idea is that because a picture book page typically has objects or abstract shapes arranged in space, an adult reader can always ask the child to count them, or talk about their location (for example, "The hat is on top of his head"). In other words, adults can interject math conversation in virtually every single book ever written because "Mathematics is all around us" (or at least we can find mathematics all around us if we have a mind to), including in picture books. At the same time, we should not ruin an interesting story by interjecting math for its own sake. Occasionally, the adult might point to some math in an "everything else" story, but in general it's not a good idea to do so: the primary goal should be to enjoy and explore the story.

Given the popularity of picture books, and given many adults' fear and dislike of mathematics, reading storybooks can be a kind of stealth weapon in teaching mathematics. For this reason the DREME project offers materials designed to help students learn how to read storybooks to further mathematics learning. 
I have found that an effective way to begin is to jump right in and read a picture book together as a whole-class activity. While ultimately the students will be presented with a guide to help them analyze books on their own, this introduction can be exploratory. The book is basically one well worth reading: it has many positive qualities, like an interesting story, but may also include problematic text or illustrations, thus providing opportunities for an interesting whole-class discussion. After reading the book once without commentary, we examine it page by page. I ask students to look at the text, the illustrations, and point out interesting and problematic features.

After students have analyzed a picture book together, I introduce a DREME guide, How to Use Picture Books for Young Children to Teach Math (Oppenzato et al. electronic document), which is designed to help students analyze books and determine their suitability and usefulness for teaching mathematics to young children. For example, the Guide encourages students to examine carefully the relation between the picture and the text on each page, the accuracy of the mathematics presented, and other important topics. Once armed with the Guide, the students can be broken into small groups to compare and contrast a pair of books. Students are asked to consider possibilities for using different pages to promote mathematics learning.

For example, Ten Red Apples (Hutchins 2000) begins by showing ten apples on a tree. Then apples are removed from the tree, one by one, by different animals, much to the annoyance of the farmer. At one point, there are three left and then one is stolen, although the result is not shown on the page. The students can discuss how a teacher might use this page to talk about subtraction. The students learn that it wise for the teacher to begin with a series of questions that can be used both to probe and promote children's understanding of the mathematical concepts.

We should also want our students to understand that reading books with mathematics content is in many respects no different from reading other books. In both cases, the primary goal is to enjoy and learn from the books. Also, in both cases, the adult reader should employ "dialogic reading," that is, reading that engages adult and child in a dialog around reading. The adult asks questions about the book, encourages the child's attention and participation, and in general takes the child on an intellectual adventure. Most likely, your students will have studied dialogic reading in classes on literacy. In any event, the guide (Oppenzato et al. electronic document) presents the major principles of dialogic reading in the context of picture books with significant focus on math. At the same time, the adult reader should not ask so many questions that they get in the way of enjoyable book reading.

Finally, after analyzing books as a whole class and in small groups, the students select a picture book and plan a lesson around it. Later they can conduct a final class project, involving interviewing and teaching, as described earlier, on picture book reading. 


\subsection{Conclusion}

As I noted at the outset, the success of Early Mathematics Education depends in good measure on the professional development of prospective and practicing teachers in our institutions of higher learning. Teacher Educators have the opportunity and responsibility to train students to be thoughtful, sensitive, and effective guides of their children's mathematics learning. The DREME project aims to help Teacher Educators to seize the opportunity and fulfill their responsibility. We invite colleagues to share our materials and collaborate in our efforts to prepare prospective teachers to engage in exciting and meaningful mathematics education for all children.

\section{References}

Anno, M. (1977). Anno's counting book. New York: Crowell.

Baroody, A. J., \& Dowker, A. (Eds.). (2003). The development of arithmetic concepts and skills: Constructing adaptive expertise. Mahwah, NJ: Lawrence Erlbaum Associates, Publishers.

Beilock, S., Gunderson, E., Ramirez, G., \& Levine, S. (2010). Female teachers' math anxiety affects girls' math achievement. Proceedings of the National Academy of Sciences, 107(5), 1860.

Bosch, C., Álvarez Díaz, L., Correa, R., \& Druck, S. (2010). Mathematics education in Latin America and the Caribbean: A reality to be transformed (Vol. 4). Rio de Janeiro and Mexico City: ICSU-LAC/CONACYT.

Brown, M. W., \& Hurd, C. (2007). Goodnight moon. New York, NY: HarperCollins.

Carle, E. (1987). Rooster's off to see the world. Natick, MA: Picture Book Studio.

Casey, B., Kersh, J. E., \& Young, J. M. (2004). Storytelling sagas: An effective medium for teaching early childhood mathematics. Early Childhood Research Quarterly, 19(1), 167-172.

Center for Universal Education at Brookings and UNESCO Institute for Statistics. (2013). Toward universal learning: What every child should learn. Retrieved from Washington, DC.

Cross, C. T., Woods, T. A., \& Schweingruber, H. (Eds.). (2009). Mathematics learning in early childhood: Paths toward excellence and equity. Washington, DC: National Academy Press.

Denton, K., \& West, J. (2002). Children's reading and mathematics achievement in kindergarten and first grade. Washington, DC: National Center for Education Statistics.

Duncan, G. J., Dowsett, C. J., Claessens, C., Magnuson, K., Huston, A. C., Klebanov, P., ... Japel, C. (2007). School readiness and later achievement. Developmental Psychology, 43(6), 14281446.

Duncan, G. J., \& Magnuson, K. (2011). The nature and impact of early achievement skills, attention skills, and behavior problems. In G. J. Duncan \& R. J. Murnane (Eds.), Whither opportunity: Rising inequality, schools, and children's life chances (pp. 47-69). New York, NY: Russell Sage.

Franke, M. L. (electronic document). Counting collections. Retrieved from http://prek-math-te. stanford.edu/counting/counting-collections-overview.

Ginsburg, H. P. (1997). Entering the child's mind: The clinical interview in psychological research and practice. New York: Cambridge University Press.

Ginsburg, H. P. (electronic document-a). Ben learns how many. Retrieved from http://prek-mathte.stanford.edu/counting/ben-learns-how-many.

Ginsburg, H. P. (electronic document-b). Math thinking conversations. Retrieved from http://prekmath-te.stanford.edu/overview/math-thinking-conversations. 
Ginsburg, H. P. (electronic document-c). How to analyze a child's counting. Retrieved from http:// prek-math-te.stanford.edu/counting/how-analyze-childs-counting.

Ginsburg, H. P. (electronic document-d). The pedagogy of the video clip. Retrieved from http:// prek-math-te.stanford.edu/overview/pedagogy-video-clip.

Ginsburg, H. P. (electronic document-e). Ben learns how to count. Retrieved from http://prekmath-te.stanford.edu/counting/ben-learns-how-count.

Ginsburg, H. P. (electronic document-f). What young children know and need to learn about counting. Retrieved from http://prek-math-te.stanford.edu/counting/what-children-know-andneed-learn-about-counting.

Ginsburg, H. P., \& Amit, M. (2008). What is teaching mathematics to young children? A theoretical perspective and case study. Journal of Applied Developmental Psychology, 29(4), 274-285.

Ginsburg, H. P., Greenes, C., \& Balfanz, R. (2003). Big math for little kids. Parsippany, NJ: Dale Seymour Publications.

Ginsburg, H. P., Hyson, M., \& Woods, T. A. (Eds.). (2014). Preparing early childhood educators to teach math: Professional development that works. Baltimore, MD: Paul H. Brookes Publishing Co.

Ginsburg, H. P., Lee, J. S., \& Boyd, J. S. (2008). Mathematics education for young children: What it is and how to promote it. Society for Research in Child Development Social Policy ReportGiving Child and Youth Development Knowledge Away, 22(1), 1-24.

Griffin, S. (2004). Building number sense with number worlds: A mathematics program for young children. Early Childhood Research Quarterly, 19(1), 173-180.

Heritage, M. (2010). Formative assessment: Making it happen in the classroom. Thousand Oaks, CA: Corwin.

Hutchins, P. (2000). Ten red apples. New York, NY: Greenwillow Books.

James, W. (1958). Talks to teachers on psychology: And to students on some of life's ideals. New York: W. W. Norton \& Company.

Lillemyr, O. F., Fagerli, O., \& Søbstad, F. (2001). A global perspective on early childhood care and education: A proposed model. Retrieved from Paris.

Love, J. M., \& Xue, Y. (2010). How early care and education programs 0-5 prepare children for Kindergarten: Is it enough? Paper presented at the Head Start's 10th National Research Conference, Washingon, DC.

Oppenzato, C., Uscianowski, C., Almeda, V., \& Ginsburg, H. P. (electronic document). Using picture books: Counting. Retrieved from http://prek-math-te.stanford.edu/counting/usingpicture-books-counting.

Piaget, J. (1952). The child's conception of number (C. Gattegno \& F. M. Hodgson, Trans.). London: Routledge \& Kegan Paul Ltd.

Piaget, J. (1976). The child's conception of the world (J. Tomlinson \& A. Tomlinson, Trans.). Totowa, NJ: Littlefield, Adams \& Co.

Piaget, J., \& Inhelder, B. (1969). The psychology of the child (H. Weaver, Trans.). New York: Basic Books, Inc.

Platas, L. M. (electronic document-a). But, I'm not good at math! Retrieved from http://prek-mathte.stanford.edu/counting/im-not-good-math-activity.

Platas, L. M. (electronic document-b). The mathematics of counting. Retrieved from http://prekmath-te.stanford.edu/counting/mathematics-counting-0.

Platas, L. M. (electronic document-c). "Engaging Mathematics" Activity. Retrieved from http:// prek-math-te.stanford.edu/counting/engaging-mathematics-activity.

Platas, L. M., Ketterlin-Geller, L. R., \& Sitabkhan, Y. (2016). Using an assessment of early mathematical knowledge and skills to inform policy and practice: Examples from the early grade mathematics assessment. International Journal of Education in Mathematics, Science and Technology, 4(3), 163-173.

Sarama, J., \& Clements, D. H. (2004). Building blocks for early childhood mathematics. Early Childhood Research Quarterly, 19(1), 181-189. 
Sarama, J., \& Clements, D. H. (2009). Early childhood mathematics education research: Learning trajectories for young children. New York: Routledge.

Schwartz, D. L., \& Bransford, J. D. (1998). A time for telling. Cognition and Instruction, 16(4), $475-422$.

Sophian, C. (2004). Mathematics for the future: Developing a head start curriculum to support mathematics learning. Early Childhood Research Quarterly, 19(1), 59-81.

Starkey, P., Klein, A., \& Wakeley, A. (2004). Enhancing young children's mathematical knowledge through a pre-kindergarten mathematics intervention. Early Childhood Research Quarterly, 19(1), 99-120.

Vygotsky, L. S. (1986). Thought and language (A. Kozulin, Trans.). Cambridge, MA: The MIT Press.

Open Access This chapter is licensed under the terms of the Creative Commons Attribution 4.0 International License (http://creativecommons.org/licenses/by/4.0/), which permits use, sharing, adaptation, distribution and reproduction in any medium or format, as long as you give appropriate credit to the original author(s) and the source, provide a link to the Creative Commons license and indicate if changes were made.

The images or other third party material in this chapter are included in the chapter's Creative Commons license, unless indicated otherwise in a credit line to the material. If material is not included in the chapter's Creative Commons license and your intended use is not permitted by statutory regulation or exceeds the permitted use, you will need to obtain permission directly from the copyright holder.

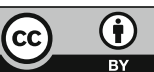

